\title{
Quiescence and Activation of Stem and Precursor Cell Populations in the Subependymal Zone of the Mammalian Brain Are Associated with Distinct Cellular and Extracellular Matrix Signals
}

\author{
Ilias Kazanis, ${ }^{1 *}$ Justin D. Lathia, ${ }^{1,2 *}$ Tegy J. Vadakkan, ${ }^{3}$ Eric Raborn, ${ }^{4,5,6}$ Ruiqian Wan, ${ }^{2}$ Mohamed R. Mughal, ${ }^{2}$ \\ D. Mark Eckley, ${ }^{7}$ Takako Sasaki, ${ }^{8}$ Bruce Patton, ${ }^{9}$ Mark P. Mattson, ${ }^{2}$ Karen K. Hirschi, ${ }^{4,5,6}$ Mary E. Dickinson, ${ }^{3}$ \\ and Charles ffrench-Constant ${ }^{1,10}$ \\ ${ }^{1}$ Department of Pathology, University of Cambridge, Cambridge CB2 1QP, United Kingdom, 22Laboratory of Neurosciences, National Institute on Aging \\ Intramural Research Program, Baltimore, Maryland 21224, Departments of ${ }^{3}$ Molecular Physiology and Biophysics, ${ }^{4}$ Pediatrics, and ${ }^{5}$ Molecular and Cellular \\ Biology and ${ }^{6}$ Center for Cell and Gene Therapy, Baylor College of Medicine, Houston, Texas 77030, ${ }^{7}$ Laboratory of Genetics, National Institute on Aging \\ Intramural Research Program, Baltimore, Maryland 21224, ${ }^{8}$ Department of Biochemistry and Molecular Biology and ${ }^{9}$ Center for Research on Occupational \\ and Environmental Toxicology, Oregon Health and Science University, Portland, Oregon 97239, and ${ }^{10}$ Medical Research Council Centre for Regenerative \\ Medicine, Queen's Medical Research Institute, Little France Crescent, Edinburgh EH16 4TJ, United Kingdom
}

The subependymal zone (SEZ) of the lateral ventricles is one of the areas of the adult brain where new neurons are continuously generated from neural stem cells (NSCs), via rapidly dividing precursors. This neurogenic niche is a complex cellular and extracellular microenvironment, highly vascularized compared to non-neurogenic periventricular areas, within which NSCs and precursors exhibit distinct behavior. Here, we investigate the possible mechanisms by which extracellular matrix molecules and their receptors might regulate this differential behavior. We show that NSCs and precursors proceed through mitosis in the same domains within the SEZ of adult male mice-albeit with NSCs nearer ependymal cells — and that distance from the ventricle is a stronger limiting factor for neurogenic activity than distance from blood vessels. Furthermore, we show that NSCs and precursors are embedded in a laminin-rich extracellular matrix, to which they can both contribute. Importantly, they express differential levels of extracellular matrix receptors, with NSCs expressing low levels of $\alpha 6 \beta 1$ integrin, syndecan-1, and lutheran, and in vivo blocking of $\beta 1$ integrin selectively induced the proliferation and ectopic migration of precursors. Finally, when NSCs are activated to reconstitute the niche after depletion of precursors, expression of laminin receptors is upregulated. These results indicate that the distinct behavior of adult NSCs and precursors is not necessarily regulated via exposure to differential extracellular signals, but rather via intrinsic regulation of their interaction with their microenvironment.

\section{Introduction}

Stem cell niches are protective microenvironments constructed by supporting cells and-in vertebrates- blood vessels, that contain stem cells and some of their progeny (Scadden, 2006; Kiel et al., 2007). A neurogenic stem cell niche in the adult rodent brain is the subependymal zone (SEZ) of the lateral walls of the lateral

Received Feb. 8, 2010; revised April 26, 2010; accepted May 6, 2010.

J.D.L. was supported by the National Institutes of Health (NIH)-Cambridge Graduate Partnership Program. B.L.P. is supported by grants from the NIH (NS40759) and National Science Foundation (9876771). C.ff.-C. is supported by the Wellcome Trust and the Medical Research Council. This work was supported by the National Institutes of HealthNational Institute of Biomedical Imaging and Bioengineering Quantum Grant Project (1P20EB00706) and the $\mathrm{Na}-$ tional Institute on Aging Intramural Research Program. We thank Dr. Badrinath Roysam for sharing the FARSIGHT software and Dr. L. Sorokin (University of Lund, Lund, Sweden) and Dr. J. Miner (Washington University, St. Louis, MO) for the kind offer of antibodies.

*I.K. and J.D.L. contributed equally to this work.

Correspondence should be addressed to Dr. llias Kazanis, Department of Pathology, University of Cambridge, Tennis Court Road, Cambridge CB2 1QP, UK. E-mail: ik255@cam.ac.uk.

Justin D. Lathia's present address: Department of Stem Cell Biology and Regenerative Medicine, Lerner Research Institute, Cleveland Clinic, Cleveland, OH 44195.

DOI:10.1523/JNEUROSCI.0700-10.2010

Copyright $\odot 2010$ the authors $\quad$ 0270-6474/10/309771-11\$15.00/0 ventricles (LVs). Here, astroglial-like neural stem cells (NSCs, also known as type B cells) generate neuroblasts (NBs, or type A cells) and oligodendrocyte precursors via transit-amplifying precursors (TaPs, or type C cells) (Doetsch et al., 1999). The cell cycle behavior of NSCs and of their downstream more committed progenitors (collectively referred to as "precursors") within the niche is distinct. In the normal CNS, NSCs are relatively quiescent, while precursors actively proliferate (Morshead et al., 1994). Following ablation of the precursors, however, the NSCs become activated and rapidly generate a new population of TaPs. However, the intrinsic and extrinsic signals that determine these distinct behaviors remain elusive.

A necessary first step in determining the identity of these signals is to establish the cellular and extracellular environment of NSCs and TaPs. Previous studies have shown that proliferating cells in the SEZ reside in close proximity to blood vessels (Shen et al., 2008; Tavazoie et al., 2008) and to fractones (Kerever et al., 2007), extracellular matrix (ECM) structures proposed to be continuums of the blood vessel basement membrane, and that NSCs 
intercalate between ependymal cells creating specific pinwheel cytoarchitectures at the ventricular wall (Mirzadeh et al., 2008). However, these studies did not examine whether NSCs and TaPs differed in their proximity to ependymal cells and blood vessels, critical information in the formulation of hypotheses as to which cell type generates the signals for each stem/precursor population. Nor, in addition, was the role of ECM examined by determining expression of its components and their receptors. Here we have performed this analysis and show that, while stem and precursor cells are equidistant from blood vessels, stem cells are also in close proximity to ependymal cells. Laminins are expressed throughout the niche but only precursors express laminin binding integrins in the normal CNS, and functional studies show that these regulate proliferation and migration. During regeneration NSCs also express integrins, and our study therefore shows for the first time how laminins could regulate proliferation of the different populations in the niche during maintenance and regeneration.

\section{Materials and Methods}

Tissue preparation and immunostaining. Experiments were performed in accordance with the Animals (Scientific Procedures) Act (1986). Adult (4-6 months) C57BL/6 and 129sv male mice were fixed in $4 \%$ paraformaldehyde in PBS. Cryostat $(6 \mu \mathrm{m})$ or vibratome $(70 \mu \mathrm{m})$ brain sections were cut from the area extending from bregma up to $2.0 \mathrm{~mm}$ posterior. For immunostaining, sections were treated with $0.1 \%$ Triton X-100, 10\% normal goat serum (Sigma) in PBS and subsequently incubated overnight with the appropriate primary antibodies at $4^{\circ} \mathrm{C}$ (antibodies used are listed in supplemental Table 1, available at www.jneurosci.org as supplemental material). For laminin immunostaining, sections were also postfixed with acetone (10 $\mathrm{min}$ ) and the blocking buffer contained 3\% BSA (Sigma). Alexa Fluor 350, 488, 568, and 647 (Invitrogen) were used as secondary antibodies. To identify slowly dividing, BrdU-retaining cells, mice received $2 \mathrm{BrdU}$ injections/d (Sigma; $50 \mathrm{mg} / \mathrm{kg}$ of body weight) for $3 \mathrm{~d}$ and were killed $40 \mathrm{~d}$ later. Brains were processed and analyzed as described above with the addition of a pretreatment in $2 \mathrm{~N} \mathrm{HCl}$ for $30 \mathrm{~min}$ at $37^{\circ} \mathrm{C} . \mathrm{HCl}$ treatment resulted in significant alterations of the immunostaining for most laminins and laminin receptors; therefore, only the $\mathrm{BrdU} / \beta 1$ integrin double staining results have been incorporated to the analysis. Images were acquired using an Olympus IX50 or a Zeiss fluorescence microscope and with a Leica SP5 confocal microscope and were processed using MagnaFire and Photoshop (Adobe) software. Triple labelings were analyzed using DeltaVision imaging as previously reported (Lathia et al., 2007). Briefly, an Olympus IX60 inverted microscope was used as the platform for image acquisition (Applied Precision). The interface for stack building was done with a SoftWorx acquisition module (Resolve3D). The center of an image stack was determined by the autofocus function of Resolve3D and images were automatically compiled into interleaved color stacks from that plane outward using a custom script. Tiffs were generated via a SoftWorx command and exported to Adobe Photoshop for figure assembly. Each experimental image was acquired as a stack of $100 \mathrm{~nm}$ slices with 20 slices per cell using a $60 \times$ objective. Images were displayed using the medium intensity quick projection function.

For the structural analysis, coronal vibratome sections, rather than SEZ whole mounts, were used so as to allow comparison of the neurogenic niche with neighboring non-neurogenic striatal and periventricular areas. While this is advantageous, we considered two possible limitations introduced by the use of coronal sections - the loss of adjacent structures such as blood vessels due to separation by the plane of section and the possibility of the microvessel densities being unrepresentative due to the limited volume of the section. For the analysis of the position of dividing cells, all work was therefore done with confocal microscope $z$-stacks from $70 \mu \mathrm{m}$ sections, and in measuring the proximities of the nuclei to the nearest blood vessel, we excluded those nuclei that were $<10 \mu \mathrm{m}$ from the edge of the $z$-stacks if the distance to the vessel was $>20 \mu \mathrm{m}$, as for these cells the nearest vessel may not be present in the $z$-stack. Based on our measurements the density of vessels in the SEZ is $2.5 \%$. Hence the error introduced by cutting off vessels in the coronal sections is $\sim 3 \%$. Additionally, since we are excluding the cells on the boundary, the error in the measurements of the proximities that may be caused by the finite size of the coronal sections is further reduced. When the densities of microvessels were calculated, these were not equal in all $z$-stacks-however, this variability is also present in whole mounts, and there was no significant difference in the mean vessel densities we measured using coronal sections and whole-mount sections (data not shown).

Stainings were imaged using a confocal microscope (LSM 510 META, Carl Zeiss) with a Plan-Apochromat 63 X/1.4 oil DIC objective lens. Images were analyzed using automated image processing software FARSIGHT (Charbord and Moore, 2005). The cell types in a multichannel image were enumerated as described below. First, all the DAPIstained nuclei in an image were counted using FARSIGHT. In the case of nuclear markers, all the nuclei above a certain intensity threshold in the corresponding channels were counted. For membrane markers, boundary pixels of the DAPI-stained nuclei were inspected and the nuclei were deemed positive or negative if the pixels were above or below an intensity threshold. The fraction of a cell type in the SEZ was defined as the ratio of the total number of nuclei counted from various images to the total number of DAPI-stained nuclei in the corresponding images. The cell types were cataloged from a pool of 2200 cells in the SEZ. To measure the distance of the various cell types to the blood vessels, the nuclei were segmented as described above, the vessels were then segmented, and the distances from the centroid of the nuclei to the surface of the vessels were measured using FARSIGHT. The density of vessels was measured using a custom program written in MATLAB, and vessel diameters as well as the proximity of vessels to the ventricle were measured using LSM image browser from $60 z$-stacks that were $10-45 \mu \mathrm{m}$ thick. The size of each image that was analyzed was $143 \mu \mathrm{m}$ (parallel to the lateral ventricles) $\times$ $20 \mu \mathrm{m}$ (distance from the ventricle). The measurements involving GFAP immunostaining were made using Imaris 5.0.3.

AraC treatment and $\beta 1$ integrin-blocking experiments. Adult mice were anesthetized and a cannula (BIK-II, Alzet) was fixed on the skull (1 mm lateral to bregma) connected to a subcutaneously implanted miniosmotic pump (1007D, Alzet). For AraC treatment, 4\% AraC (Sigma) or saline alone was infused for $4 \mathrm{~d}$ onto the surface of the brain and animals were killed at different time points after the end of the infusion (Kazanis et al., 2007). For $\beta 1$ integrin-blocking experiments, isotype-control or blocking antibodies (clone Ha2/5, BD Biosciences PharMingen) were infused for $3 \mathrm{~d}$ in one ventricle and mice were killed 1 or $4 \mathrm{~d}$ after treatment.

Fluorescence-activated cell sorting and neurosphere assays. The SEZ from 10- to 12-week-old heterozygous Sox2:EGFP (Ellis et al., 2004) and CD1 male mice was microdissected into DMEM/F12 (Sigma). Samples were digested with papain (Worthington) for 30-45 min with occasional resuspension (Panchision et al., 2007; Coskun et al., 2008). The sample was passed through a $40 \mu \mathrm{m}$ filter to exclude undigested tissue and large debris and the cell concentration adjusted to $10^{6}$ cells $/ 100 \mu \mathrm{l}$ for staining. Cell suspensions were incubated with antibodies against $\beta 1$ integrin conjugated to Alexa Fluor 700 (Biolegend) at a concentration of 1:100 on ice for $20 \mathrm{~min}$. Propidium iodide was added (1:100), at least $10 \mathrm{~min}$ before sorting, to exclude dead or dying cells. Experiments were performed with a BD FACSaria machine. Samples from wild-type mice were used as negative controls to set up voltages and to establish positive and negative gates (supplemental Fig. 1, available at www.jneurosci.org as supplemental material). Data were collected using FACSdiva software and analyzed using Flowjo software. Sorted cells were plated at clonal density (50 cells/ $\mathrm{cm}^{2}$ ) (Coskun et al., 2008) in neurosphere medium (containing FGF2 and EGF). Fresh medium was added after $3 \mathrm{~d}$ to maintain growth factor concentrations and the sphere forming potential was assessed at $7 \mathrm{~d}$. Single primary spheres were placed in individual wells of a 96-well plate and dissociated into single cells to assess formation of secondary spheres. 


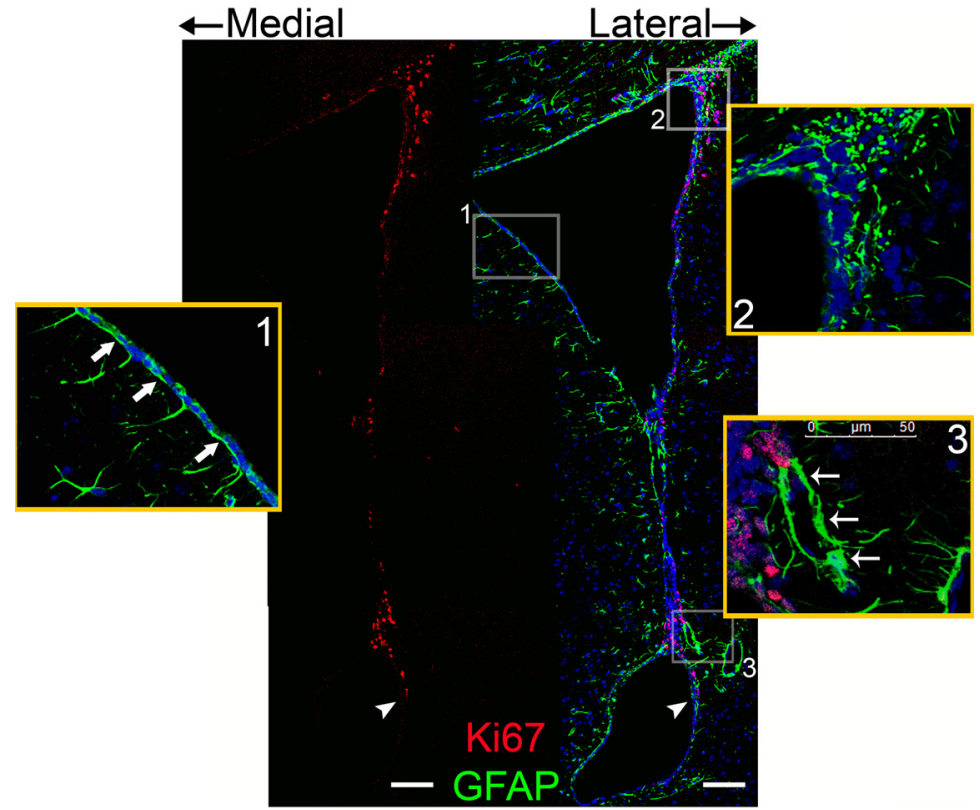

Figure 1. Structural characteristics of the SEZ. Two low-power views of a coronal section showing the entire lateral ventricle of the adult mouse brain are shown, single labeled on the left for Ki67 (red) and double labeled for Ki67 and GFAP (green) on the right. As indicated, medial is to left, lateral to the right. Note that proliferation (KI67+ cells) occurs only immediately adjacent to the lateral side of the ventricle, extending almost the entire length of the lateral side - the basal limit of proliferation is marked by the arrowhead. GFAP labeling reveals structural differences between the two sides; at the medial (non-neurogenic) side, ependymal cells are underlined by astrocytic processes (box 1, shown in higher power in inset 1, arrows show GFAP + astrocyte processes), a cytoarchitecture absent from the neurogenic side (box 2, shown in higher power in inset 2 - note the lack of astrocyte processes running parallel to the ventricular surface). GFAP + processes can also be seen surrounding blood vessels (box 3 , shown in higher power in inset 3). Note here that proliferating cells reside next to blood vessels but are only seen up to a certain distance from the ventricle, as revealed by their absence from the lateral side of the blood vessel (indicated by arrows in inset 3). Scale bars, $100 \mu \mathrm{m}$.

\section{Results}

\section{Structural characteristics of the neurogenic niche}

The SEZ neurogenic niche is a narrow periventricular area extending a few micrometers into the mature brain tissue at the lateral side of the LV wall, with the middle and ventral parts being thin and compact areas and the dorsal part being wider and dominated by large clusters of migrating NBs (Fig. 1 and supplemental Fig. 2, available at www.jneurosci.org as supplemental material). We compared the structure of the SEZ on the lateral side of the LV with the non-neurogenic area situated at the medial side (middle and dorsal parts) of the SEZ (Fig. 1), focusing on the ependymal cells, astrocytes, and vasculature. Ependymal cells form a monolayer that lines the ventricle, and at the medial side below the ependymal layer multiple astrocytes form a layer of processes running in parallel to the ventricular wall (Fig. 1, inset 1 ). This ependymal-astrocyte architecture was not observed in the SEZ, where astroglial processes run radially, or randomly (Fig. 1, inset 2). The SEZ niche was also characterized by an extensive network of blood vessels, many positioned in parallel to the ventricle (supplemental Fig. 3, available at www.jneurosci.org as supplemental material). Using image processing software (see Materials and Methods), we compared the vessel network on the lateral and medial sides throughout a range of dorsoventral and rostrocaudal levels [from bregma $(0 \mathrm{~mm})$ to $2.0 \mathrm{~mm}$ rostrally)] ( $n=6$ mice). The vessel network in the SEZ was positioned nearer to the ventricle (average distance was $12.06 \pm 4.07 \mu \mathrm{m}$, vs $21.15 \pm 10.43 \mu \mathrm{m}$ at the medial side, $p<0.02$ using the KruskalWallis test), with the shortest distance of vessels from the ventricle also being significantly smaller $(10.21 \pm 2.56 \mu \mathrm{m}$ compared to $20.07 \pm 8.64 \mu \mathrm{m}$ at the medial side). Therefore, the area that encompasses the niche is significantly more vascularized than the medial side (with vessels representing $2.48 \pm 1.65 \%$ of the tissue volume on the lateral side vs $0.42 \pm 0.39 \%$ on the medial side; $p<0.01$ using the Kruskal-Wallis test), even though the average diameter of vessels was similar $(5.75 \mu \mathrm{m} \pm 1.85$ medially and 4.64 $\mu \mathrm{m} \pm 1.85$ laterally). Based on the above mapping, vascularization of the SEZ appeared to be stratified and could be divided (for analysis reasons) into four layers, each one being $5 \mu \mathrm{m}$ thick. The first comprised the ependymal cell layer and was totally devoid of blood vessels. The second layer showed the major differences with blood vessels seen in the SEZ but not on the non-neurogenic side. In both regions, however, the third and fourth layers were highly vascular.

\section{Mitotic activity of NSCs and precursors occurs in the same microdomains of the SEZ}

Having defined the position of ependymal cells and blood vessels within the SEZ, we next asked whether the location of NSCs and TaPs relative to these structural components suggested a dominant role for one or the other in providing a cellular environment for neurogenesis. First, we established the number of the different cell types within the SEZ using an automated object recognition software (FARSIGHT): ependymal cells (33\%), TaPs (12\%), NBs (23\%; commonly found in clusters), astrocytes including NSCs (16\%), neurons (11\%), and unidentified cells (5\%) (for cell-typespecific markers, see supplemental Fig. 2, available at www.jneurosci. org as supplemental material) - figures that agree closely with previous studies (Doetsch et al., 1997).

Our analysis then focused primarily on mitotic cells (i.e., the "real-time" neurogenic activity as opposed to cells that might be resting in $G_{1}$ phase of the cell cycle), marked by the expression of phosphorylated histone 3 ( $\mathrm{PH} 3$ ). We used expression of GFAP to distinguish the combined population of TaPs and NBs (that are GFAP negative) from the NSCs (that are GFAP positive), so enabling the necessary triple labeling experiments for the structural analysis using antibodies against $\mathrm{PH} 3$ and laminins (to identify blood vessels). The addition of antibodies against further markers that distinguish between TaPs and NBs resulted in a level of signal inadequate for analysis. One hundred fifty-seven mitotic cells from seven mice were identified and separated into potential NSCs (coexpressing GFAP) or more committed precursors (GFAP negative). For the analysis of the positional characteristics of different cell types, the shortest distance from the center of the nucleus of each $\mathrm{PH} 3+$ cell to the ventricle and to the nearest blood vessel was measured (supplemental Fig. 4, available at www.jneurosci.org as supplemental material), using FARSIGHT. As expected, the vast majority of mitotic cells were GFAP negative $(91 \pm 2 \%)$ and they were observed at all rostrocaudal and dorsoventral levels, although with lower average density at the middle of the niche, while no GFAP+ mitotic cells were observed in the ventral SEZ (supplemental Fig. 4, available at www.jneurosci.org as supplemental material). 
Table 1. Expression profile of ECM molecules in the normal and regenerating SEZ

\begin{tabular}{|c|c|c|c|c|c|c|c|}
\hline & \multicolumn{4}{|l|}{ Normal } & \multicolumn{3}{|l|}{ Post-AraC } \\
\hline & Ependymal cell layer & SEZ & b.v. & Fr. & Ependymal cell layer & SEZ & b.v. \\
\hline Laminin $\alpha 1$ & $\mathrm{n}$ & $n$ & $\mathrm{n}$ & $\mathrm{n}$ & $\mathrm{n}$ & $\mathrm{n}$ & $\mathrm{n}$ \\
\hline Laminin $\alpha 2$ & Diffuse & Diffuse & High & $p$ & Diffuse & $n$ & High \\
\hline Laminin $\alpha 3$ & $n$ & $n$ & $n$ & $n$ & $\mathrm{n}$ & $n$ & $n$ \\
\hline Laminin $\alpha 4$ & Diffuse & Diffuse & High & $p$ & Diffuse & $\mathrm{n}$ & High \\
\hline Laminin $\alpha 5$ & Diffuse & Diffuse & High & $p$ & Diffuse & $\mathrm{n}$ & High \\
\hline Laminin $\beta 1$ & Diffuse & Diffuse & High & $p$ & Diffuse & Astrocyte related & High \\
\hline Laminin $\beta 2$ & $n$ & Low & High & $n$ & Diffuse & $\mathrm{n}$ & High \\
\hline Laminin $\gamma 1$ & Diffuse & Diffuse & High & $p$ & Diffuse & $\mathrm{n}$ & High \\
\hline Laminin $\gamma 2$ & Diffuse & Diffuse & High & $p$ & Diffuse & $n$ & High \\
\hline Laminin $\gamma 3$ & Diffuse & Diffuse & High ( 5\%) & $p$ & Diffuse & $n$ & High ( 5\%) \\
\hline Agrin & $n$ & $n$ & High & $\mathrm{n}$ & $\mathrm{n}$ & $n$ & High \\
\hline Collagen IV & $\mathrm{n}$ & $\mathrm{n}$ & High & $n$ & $\mathrm{n}$ & $\mathrm{n}$ & High \\
\hline Fibronectin & $n$ & $\mathrm{n}$ & High & $\mathrm{n}$ & $\mathrm{n}$ & $\mathrm{n}$ & High \\
\hline CSPG & Diffuse & $\mathrm{n}$ & High & $n$ & Diffuse & $\mathrm{n}$ & High \\
\hline Kalanin & $n$ & $\mathrm{n}$ & $\mathrm{n}$ & $n$ & $n$ & $\mathrm{n}$ & $\mathrm{n}$ \\
\hline Nidogen-1 & $n$ & $n$ & $n$ & $n$ & $\mathrm{n}$ & $\mathrm{n}$ & $n$ \\
\hline Perlecan & $n$ & $n$ & $n$ & $n$ & $\mathrm{n}$ & $\mathrm{n}$ & $n$ \\
\hline
\end{tabular}

Note the decrease in laminin immunoreactivity in the SEZ after treatment with AraC. b.v., Blood vessels; Fr., fractones; $n$, negative; $p$, positive.

All mitotic cells were located within a 20 - $\mu$ m-wide zone adjacent to the ventricle. Few mitotic nuclei were positioned among ependymal cells $(<5 \mu \mathrm{m}$ from the ventricular surface; $7 \%$ of all mitotic cells), and these included almost half of dividing astrocytes $(40 \%$ of GFAP $+/ \mathrm{PH} 3+$ cells) and a small fraction of the mitotic GFAP - cells ( $6 \%$ of GFAP $-/ \mathrm{PH} 3+$ cells). More mitotic cells $(43 \%$ of all mitotic cells) were observed in the second cell layer (5-10 $\mu \mathrm{m}$ from the ventricular surface), belonging both to $\mathrm{GFAP}+(60 \%$ of GFAP $+/ \mathrm{PH} 3+$ cells $)$ and GFAP $-(42 \%$ of $\mathrm{GFAP}-/ \mathrm{PH} 3+)$ cells. Reflecting this, the average distances from the ventricle were $7.2 \pm 1.5 \mu \mathrm{m}$ for the mitotic GFAP + cells (NSCs) and $10.7 \pm 4.3 \mu \mathrm{m}$ for the mitotic GFAP - precursors ( $p=0.316$ using the nonparametric Friedman test). The third and fourth cell layers $(10-20 \mu \mathrm{m})$ contained numerous GFAPmitotic nuclei $(35 \%$ and $17 \%$ of GFAP-/PH3 + cells, respectively) but no mitotic astrocytes, although these layers were rich in nondividing astrocytes (containing $25 \%$ of all SEZ astrocytes, with another $9 \%$ positioned farther than $20 \mu \mathrm{m}$ ). These data therefore demonstrate that neurogenic activity (either of NSCs or downstream precursors) occurs in the periventricular area, with the GFAP + mitotic cells (NSCs) restricted to the $10 \mu \mathrm{m}$ adjacent to the ventricle while the GFAP - cells (precursors) are dispersed throughout the $20 \mu \mathrm{m}$ depth of the SEZ.

Having established above that the neurogenic regions of the SEZ are more vascularized than non-neurogenic regions, we next examined the position of the mitotic cells relative to blood vessels. The average distance of mitotic NSCs, mitotic precursors, and nonmitotic astrocytes from the nearest blood vessel was not statistically different (NSCs: $16.6 \pm 15.4 \mu \mathrm{m}$, precursors: $13.7 \pm$ $10.6 \mu \mathrm{m}$, nonmitotic astrocytes: $16.8 \pm 10.7 \mu \mathrm{m} ; p=0.12 \mathrm{using}$ the nonparametric Friedman test), and we observed significant numbers of mitotic NSCs and precursors at distances $>20 \mu \mathrm{m}$ from the nearest blood vessel (NSCs: $20 \% 0-5 \mu \mathrm{m}, 30 \%$ 5-10 $\mu \mathrm{m}$, and 50\% > $20 \mu \mathrm{m}$; precursors: $29 \% 0-5 \mu \mathrm{m}, 19 \%$ 5-10 $\mu \mathrm{m}$, $6 \% 10-15 \mu \mathrm{m}, 23 \% 15-20 \mu \mathrm{m}$, and $23 \%>20 \mu \mathrm{m})$. Indeed, when the distance from the ventricle and from the nearest blood vessel was compared for each mitotic cell, using the nonparametric paired Wilcoxon test, it was found that both mitotic NSCs and precursors were positioned significantly nearer to the ventricle rather than to blood vessels ( $p=0.007$ for NSCs and $p=0.013$ for precursors), even though many of the latter population are located $10-20 \mu \mathrm{m}$ away from the ventricle.

\section{The neurogenic microenvironment is rich in laminins}

Having established that NSCs and precursors differ in their distribution within the SEZ, we next asked whether this resulted in differences in the extracellular matrix environment of the two populations. We focused on laminins, as these molecules are found in other niches and have previously been shown to be present in fractones within the SEZ. Laminins are trimers consisting of one $\alpha$, one $\beta$, and one $\gamma$ chain, and we examined the expression of these chains using available chain-specific antibodies as detailed in Table 1. Blood vessels of the niche were immunopositive for numerous laminin chains as well as for agrin, collagen IV, and fibronectin (Table 1). No difference was detected in this ECM profile among blood vessels within the SEZ and those within the adjacent striatal area (data not shown). Examination of blood vessels revealed that laminin expression was confined at the outer surface of vessels, and GFAP + cells were often found to be in close contact with the laminin-rich zone of vessels (supplemental Fig. $3 A, B$, available at www.jneurosci.org as supplemental material). The parenchyma of the ependymal and subependymal regions was also immunopositive for the same laminins (Table 1). In contrast, in the adjacent striatal area laminin immunoreactivity was associated mainly with vessels. The immunoreactivity was diffuse within the SEZ but notably higher at the ependymal layer and around clusters of TaPs and NBs (supplemental Fig. 5, available at www.jneurosci.org as supplemental material and data not shown). In addition, immunopositive fractone-like structures were observed (Table 1; supplemental Fig. 5, available at www.jneurosci.org as supplemental material). Importantly, no differences in the chains expressed were seen between any of these regions. Overall, therefore, these data indicate that the neurogenic niche is characterized by high concentrations of laminins, as compared to adjacent non-neurogenic areas, with NSCs and precursors equally exposed to this ECM and with no differences in trimer composition as judged by the expression of specific chains.

\section{Differential expression of laminin receptors on NSCs and progenitors}

A uniform expression of laminins could still generate distinct signals in stem and precursor populations if the expression of laminin receptors differed on the two populations. We therefore performed an immunohistochemical analysis of the expression 
Table 2. Expression profile of laminin receptors in the normal and regenerating SEZ

\begin{tabular}{llllll}
\hline & $\mathrm{E}$ & $\mathrm{B}$ & TaP & NB & b.v. \\
\hline$\alpha 3$ Integrin & $\mathrm{n}$ & $\mathrm{n}$ & $\mathrm{n}$ & $\mathrm{n}$ & $\mathrm{n}$ \\
$\alpha 4$ Integrin & $\mathrm{n}$ & $\mathrm{n}$ & $\mathrm{n}$ & $\mathrm{n}$ & $\mathrm{n}$ \\
$\alpha 5$ Integrin & $\mathrm{n}$ & $\mathrm{n}$ & $\mathrm{n}$ & $\mathrm{n}$ & $\mathrm{n}$ \\
$\alpha 6$ Integrin & High & $\mathrm{n}$ & High & High & High \\
$\alpha 7$ Integrin & $\mathrm{n}$ & $\mathrm{n}$ & $\mathrm{n}$ & $\mathrm{n}$ & High \\
$\beta 1$ Integrin & High & $\mathrm{n}$ & High & High & High \\
Syndecan-1 & $\mathrm{n}$ & Low & High & High & Low \\
Lutheran & High & $\mathrm{n}$ & High & High & High \\
Dystroglycan & $\mathrm{n}$ & $\mathrm{n}$ & $\mathrm{n}$ & $\mathrm{n}$ & High \\
\hline
\end{tabular}

Note that type $B$ cells express low or nondetectable levels of laminin receptors in the normal niche. $\mathrm{E}$, Ependymal cells; $B$, type B astrocytes; b.v., blood vessels; $n$, negative.
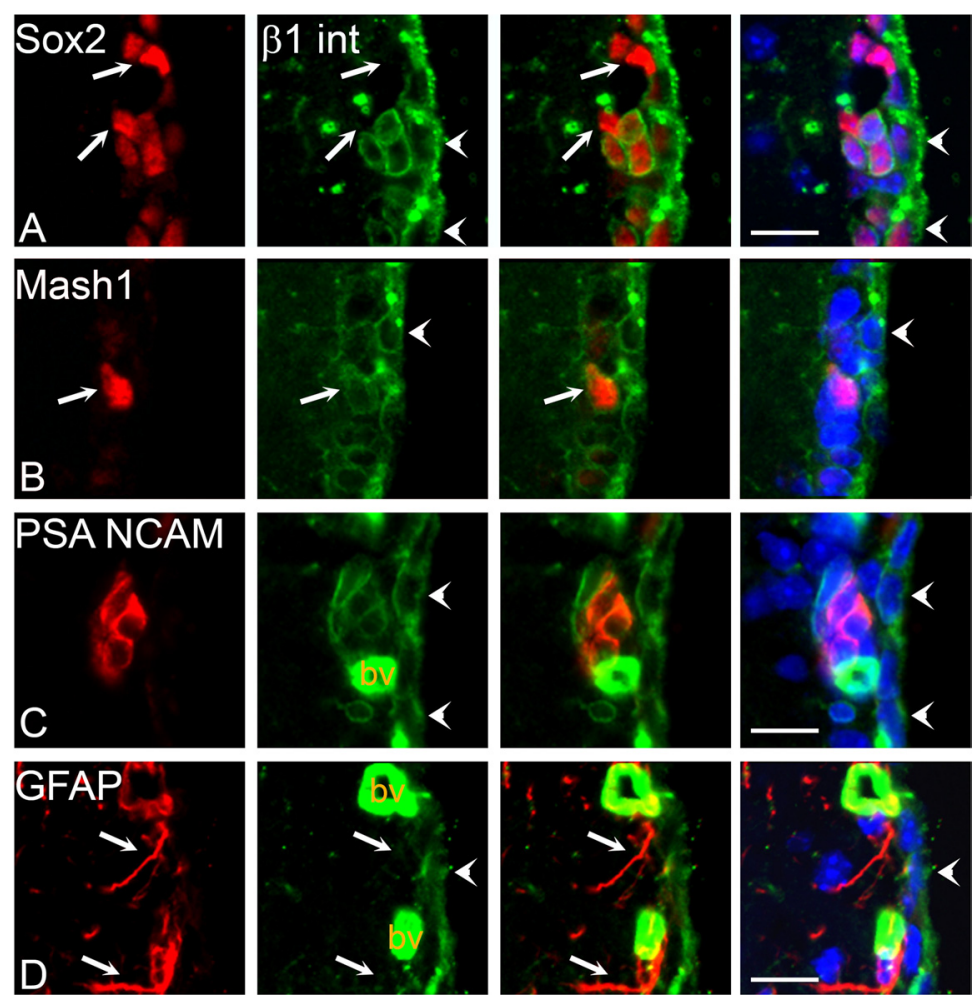

Figure 2. Cell-type-specific expression of $\beta 1$ integrin in the SEZ. Expression of $\beta 1$ integrin by different cell types of the SEZ was investigated with double immunostainings on coronal sections. Sox2 marks numerous cells within the niche $(\boldsymbol{A})$, most of which are immunopositive for $\beta 1$ integrin, although a few Sox $2+/ \beta 1$ integrin negative cells are also observed ( $A$, arrows). Transitamplifying precursors identified by Mash1 expression ( $\boldsymbol{B}$, arrow indicates 1 example) and PSA-NCAM-positive neuroblasts $(\boldsymbol{C})$ coexpress $\beta 1$ integrin. Astrocytes do not express detectable levels of $\beta 1$ integrin ( $\boldsymbol{D}$, arrows indicate $2 \beta 1$ integrin-negative astrocytes). Ependymal cells (indicated by arrowheads in all panels) and blood vessels ("bv" at $(\boldsymbol{C}$ and $\boldsymbol{D}$ ) also express high levels of $\beta 1$ integrin. The lateral ventricle is to the right in all images. Scale bar, $30 \mu \mathrm{m}$.

of the major receptors for laminins: integrins (consisting of one $\alpha$ and one $\beta$ chain), syndecans, dystroglycans, and lutheranwhich is a laminin $\alpha 5$ chain-specific ligand. The laminin receptors with the widest distribution of expression were $\alpha 6$ and $\beta 1$ integrins, expressed by blood vessels, ependymal cells, and progenitors (Table 2). Double immunostaining showed that these subunits were highly colocalized (data not shown), consistent with the expression of the laminin $\alpha 6 \beta 1$-binding integrin. Double immunostaining for $\beta 1$ integrin and the transcription factor Sox2 (expressed on NSCs, precursors, and ependymal cells) revealed that most, but not all, of Sox2-positive cells expressed $\beta 1$ integrin (Fig. $2 \mathrm{~A}$ ). To identify the integrin-negative population, we used cell-type-specific markers. These confirmed that ependymal cells, TaPs, and neuroblasts were $\beta 1$ integrin positive
(Fig. 2) and that all actively dividing cells in the SEZ expressed high levels of $\beta 1$ integrin (Fig. 3). Interestingly, however, the cell bodies and processes of astrocytes did not express $\beta 1$ integrin (Fig. 2), suggesting that the integrin-negative, Sox $2+$ cells might include the NSC population.

The finding that NSCs did not express $\beta 1$ integrin was surprising, as this integrin has been reported to be highly expressed on other stem cells. We therefore verified this conclusion in two further ways. First, we performed label-retaining studies, in which mice were given a cumulative dose of BrdU and killed $40 \mathrm{~d}$ later. This identifies the slowly dividing cell population within which NSCs will be found, while rapidly dividing precursors dilute out BrdU and so are unlabeled. In keeping with our initial results, we found that $90 \%$ of BrdUretaining cells were $\beta 1$ integrin negative (Fig. 3). As a second way to confirm this conclusion, we used a neurosphere assay. Neurospheres are three-dimensional (3D) aggregates containing a mixture of stem, precursor, and more differentiated cells that grow from a single stem cell and can be passaged to form secondary neurospheres, and therefore provide a semiquantitative method for assessing stem cell numbers within dissociated cell populations. We used fluorescence-activated cell sorting (FACS) to collect subpopulations of cells, isolated from microdissected SEZs of adult Sox2-EGFP mice and immunostained with $\beta 1$ integrin-conjugated antibodies $(n=4)$. In these mice, EGFP reporter has been shown to represent accurately endogenous Sox2 expression (Ellis et al., 2004), and we validated this within the adult SEZ by comparing EGFP expression with Sox 2 immunoreactivity (Fig. 4A). Four populations were sorted in the FACS analysis based on high or low expression of EGFP and $\beta 1$ integrin, with the EGFP $+\beta 1$ integrin - population then containing the putative GFAP+ NSCs (Figs. 2A, D, 4B), and each was collected and seeded into growth medium to assess neurosphere formation (Fig. 4C). Over 60,000 cells were assayed, and the results revealed that virtually all cells with neurosphere-forming ability were Sox $2+$ but $\beta 1$ integrin negative, with 830 of 833 spheres formed from the Sox $2+/ \beta 1$ integrin-population. Secondary spheres were formed by $83 \%$ (75/90) of primary spheres from this population. These results therefore confirmed that the Sox $2+/ \beta 1$ integrinpopulation of the SEZ is highly enriched for NSCs, and thus we conclude that the great majority of NSCs in the normal SEZ do not express detectable $\beta 1$ integrin.

Examination of other laminin receptors revealed that lutheran colocalized with $\beta 1$ integrin (supplemental Fig. 6, available at www.jneurosci.org as supplemental material). Syndecan-1 was expressed on TaPs and NBs (supplemental Fig. 7, available at www.jneurosci.org as supplemental material), but, in contrast to $\beta 1$ integrin, only low levels of expression were observed in the ependymal cell layer. Additionally, and again in contrast to $\beta 1$ integrin and lutheran, a fraction of astrocytic cell bodies and 
processes $(10 \pm 1.5 \%, n=3$ mice $)$ expressed syndecan-1. Finally, blood vessels were also immunopositive for $\alpha 7$ integrin and dystroglycan (Table 2).

There are two possible interpretations of the result that NSCs do not express detectable levels of $\beta 1$ integrin. First, $\beta 1$ integrin may be expressed only on dividing cells, and as the great majority of NSCs are quiescent, they are $\beta 1$ integrin negative. Second, NSCs and precursors may differ in integrin expression such that NSCs are always $\beta 1$ integrin negative whatever their cell cycle status. These two possibilities could in theory be distinguished in the normal niche by examining dividing NSCs, but these are very rare cells. To distinguish these possibilities, we therefore took advantage of the regenerative properties of the SEZ, where significant numbers of NSCs become activated and reenter the cell cycle to reconstitute the TaP and NB populations after their ablation with the cytotoxic drug AraC. AraC was infused on the surface of the brain for $4 \mathrm{~d}$, and mice were killed immediately after the end of treatment (day 0 , $n=5)$ and 2 or 4 d later $(n=5$ per time point). One hundred eighty-four $\mathrm{PH} 3+$ cells were identified. As expected, in these initial phases of regeneration the majority were astrocytes with their percentage declining later on (data not shown). Notably, a few mitotic astrocytes were now observed farther than $10 \mu \mathrm{m}$ from the ventricle (in contrast to the normal SEZ), but never beyond $20 \mu \mathrm{m}$ from the ventricle (the distribution was as follows: $11 \%$ 0-5 $\mu \mathrm{m}, 63 \%$ 5-10 $\mu \mathrm{m}, 22 \% ~ 10-15 \mu \mathrm{m}$, $4 \% 15-20 \mu \mathrm{m})$. As in the normal SEZ, these cells were closer to the ventricle than they were to blood vessels $(8.6 \pm 3.4 \mu \mathrm{m}$ from the ventricle and $15.8 \pm 10.5 \mu \mathrm{m}$ from the vessels; $p<0.05$ using the nonparametric Wilcoxon test). Mitotic GFAPcells were very sparse immediately after the end of AraC treatment, but their numbers increased thereafter and their distribution was similar to those of the normal niche (20\% 0-5 $\mu \mathrm{m}, 36 \%$ 5-10 $\mu \mathrm{m}, 34 \%$ $10-15 \mu \mathrm{m}, 10 \% 15-20 \mu \mathrm{m}$ from the ventricle). The expression of lutheran and syndecan-1 was upregulated on SEZ astrocytes immediately after the end of AraC infusion (Fig. 5), while expression of a $6 \beta 1$ integrin remained undetectable. However $2 \mathrm{~d}$ later, when neuroblasts were still absent and the TaP pool had only partially been reconstituted, $\beta 1$ integrin expression was upregulated on GFAP-positive cells. Triple immunostaining revealed that these $\beta 1$ integrin $+/$ GFAP + astrocytes were also Sox $2+$, confirming that
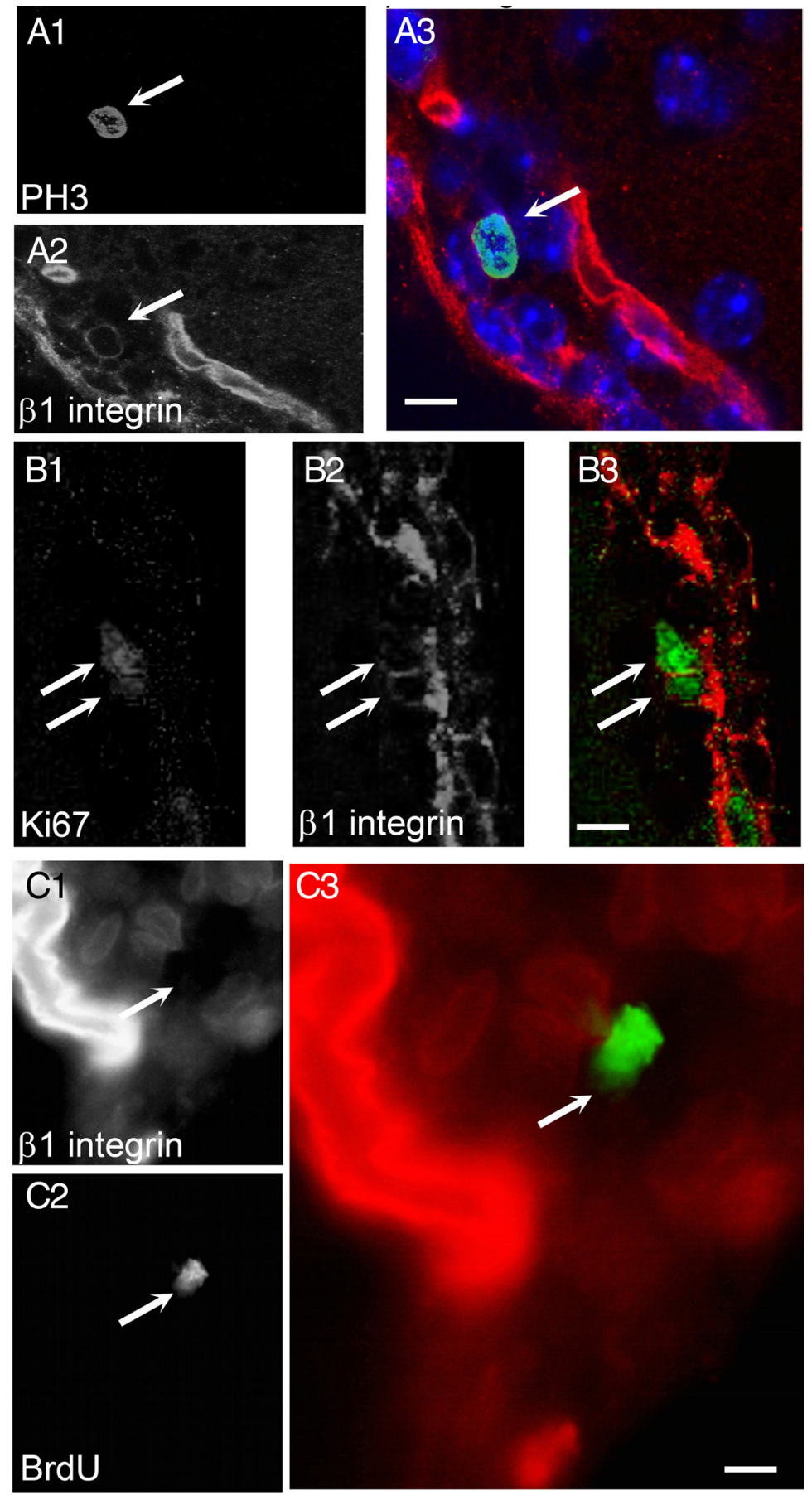

\section{BrdU}
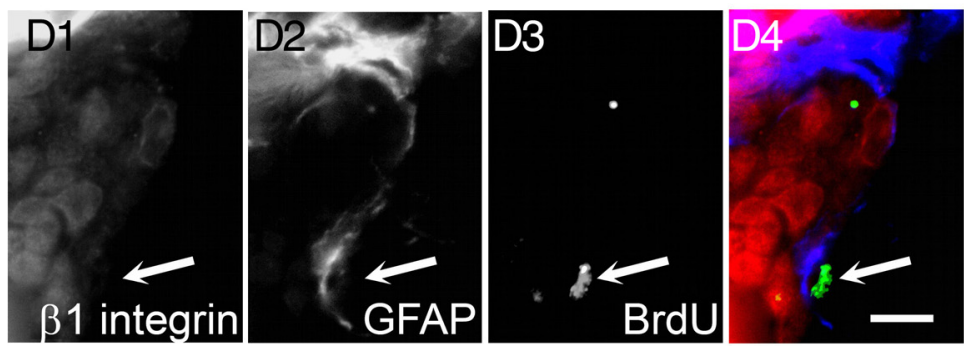

Figure 3. $\quad \beta 1$ integrin expression and cell cycle. Actively dividing cells immunolabeled with anti-phospho histone $3(\boldsymbol{A}, 1 \mathrm{PH} 3+$ cell is indicated by the arrow), or anti-Ki67 antibodies ( $\boldsymbol{B}, 2$ Ki67+ cells are indicated by arrows) express $\beta 1$ integrin. In $\boldsymbol{A 1}, \boldsymbol{A 2}, \boldsymbol{B} \mathbf{1}$, and $\boldsymbol{B 2}$, single-channel immunolabeling is shown. In $A 3$ and $B 3$, these are merged with PH3/Ki67 in green and integrin in red. Blue shows DAPl in A3. In contrast, slowly dividing cells, that retain BrdU $40 \mathrm{~d}$ after the last injection, are negative for $\beta 1$ integrin (arrows in $C$ and $D$ ). Note the presence of multiple $\beta 1$ integrin + cells in close proximity to BrdU-retaining cells. In D, the BrdU-retaining cell is also GFAP + , compatible with aNSC identity. C3 and D4 show merged images with BrdU in green, integrin in red, and in D4, GFAP in blue. Scale bars: $A, B, D, 10 \mu \mathrm{m} ; \mathbf{C}, 5 \mu \mathrm{m}$. 

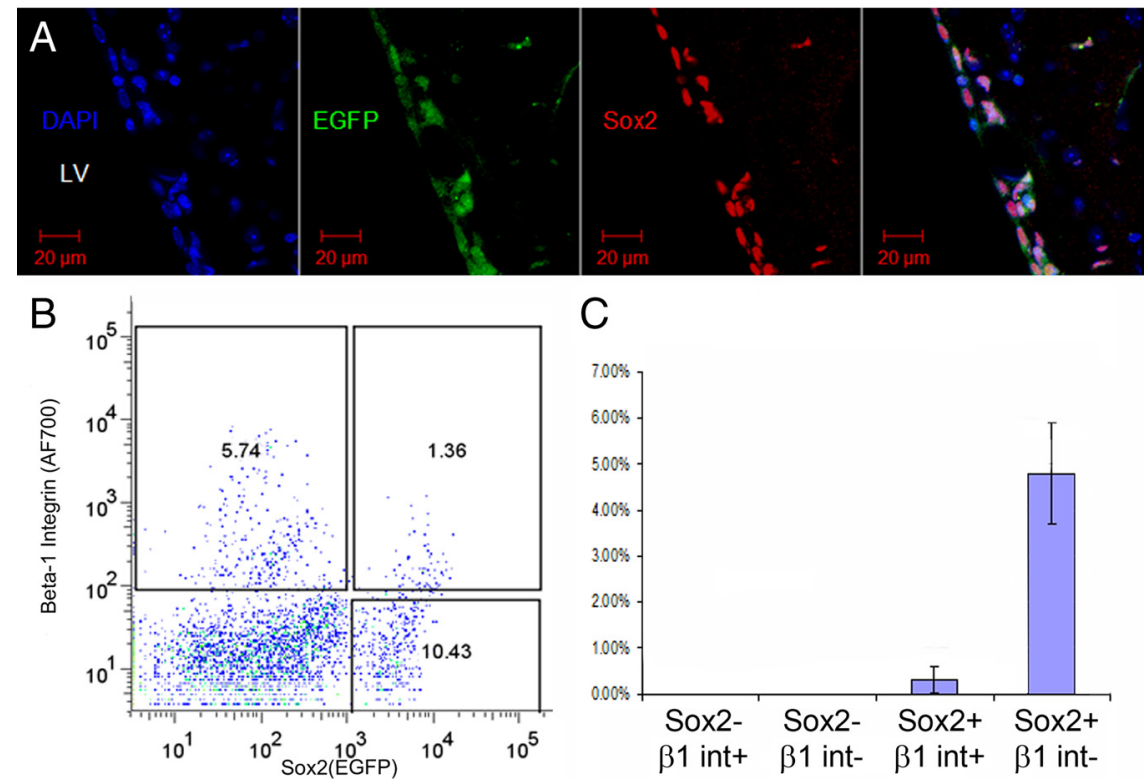

C

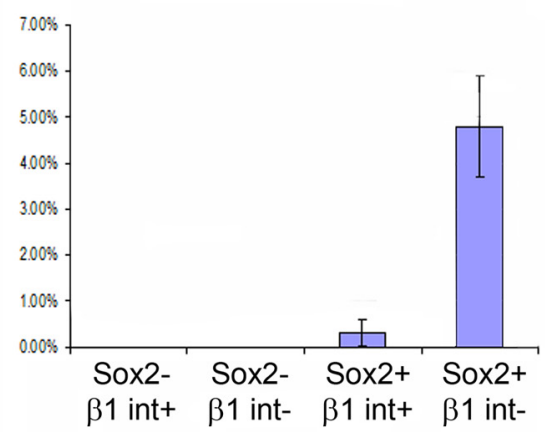

Figure 4. Sox $+/ \beta 1$ integrin-negative cells of the SEZ show high neurosphere-forming ability. $\boldsymbol{A}$, Immunofluorescence with Sox2 antibodies (red) shows colocalization with the EGFP reporter (green) in the SEZ of an adult Sox2:EGFP mouse. $\boldsymbol{B}$, Typical FACS data displaying gating for populations expressing Sox2(EGFP) and/or $\beta 1$ integrin. Four populations can be distinguished. $\boldsymbol{C}$, Percentage of cells that form neurospheres from each of the four populations shown in $\boldsymbol{B}$. Note that only Sox $2+$ cells generate neurospheres and predominantly those that are Sox $2+/ \beta 1$ integrin negative. Data in the graph represent means and SEM.

normal niche, and increased to $4.8 \pm 2 \%$ after $4 \mathrm{~d}$ with $\beta 1$ integrin-blocking antibody ( $p<0.05$ using $t$ test). In contrast, the percentage of Sox2-low/Ki67+ cells did not change significantly: $11.1 \pm 2.4 \%$ of total cells in the normal niche and $13.7 \pm 2.7$ at $4 \mathrm{~d}$ ( $p=0.54$ using $t$ test $)$. As $\sim 85 \%$ of dividing cells in the normal SEZ are neuroblasts expressing Dcx and low levels of Sox2 (supplemental Fig. 8, available at www.jneurosci.org as supplemental material), while the other $15 \%$ that express high levels of Sox 2 are predominantly TaPs (NSCs and ependymal cells that are also Sox 2 high-expressing cells divide only occasionally or are quiescent, respectively) (supplemental Fig. 8, available at www.jneurosci.org as supplemental material), we conclude that the majority of the increased proliferation is present in the TaP cells. As we would have predicted given their lack of $\beta 1$ integrin expression, there was no increase in the numbers of proliferating astrocytes (that remained $<0.5 \%$ of total cells both in the normal and the infused niche). These results therefore confirm a role for $\beta 1$ integrin in the regula-

NSCs in the SEZ niche upregulate $\beta 1$ integrin at the time of their mitotic activation (Fig. $5 E, F$ ). We conclude that integrin expression correlates with mitotic status rather than being a difference between stem and precursor cells.

Interestingly, although blood vessel- and ependymal cellrelated laminin immunoreactivity, as well as the occurrence of fractone-like dots, was unaffected by AraC treatment, there was a significant reduction in the levels of diffuse parenchymal laminin expression (Fig. 6). This indicates that TaPs and NBs (that constitute $\sim 35 \%$ of the total number of cells in the niche) contribute laminins to this compartment of the niche microenvironment. No other change in laminin expression was seen except for high levels of lamin $\beta 1$ expression that was colocalized with processes and cell bodies of astrocytes (Fig. 6).

\section{Blocking of $\boldsymbol{\beta} 1$ integrin results in increased proliferation and migration of precursors}

Having shown that $\beta 1$ integrin is expressed on mitotic stem and precursor cells, we asked what the function of these integrins was by infusing a blocking antibody into the ventricle for $3 \mathrm{~d}$ and sacrificing the mice either 1 or $4 \mathrm{~d}$ after the end of infusions. Two different concentrations of blocking antibody were administered. The high dose $(1 \mu \mathrm{g} / \mathrm{d})$ resulted in significant disorganization of the ependymal cell layer and the occurrence of big clusters of NBs in the ventricle (Fig. $7 A, B$ ), not allowing any further analysis to be performed. The infusion of lower dose of blocking antibody $(100 \mathrm{ng} / \mathrm{d})$ did not cause such profound disruption of the tissue, although some clusters of NBs were still observed within the LV. When the percentage of Ki67-positive (proliferating) cells was compared to that of the normal niche, a significant increase was found at $4 \mathrm{~d}$ after treatment $(18.6 \pm 4 \%$ compared with $13.0 \pm$ $5 \%$ of total cells in the isotype antibody infused SEZ; $p<0.05$ using one-way ANOVA). This increase in the percentage of proliferating cells after blocking of integrin- $\beta 1$ was observed almost exclusively within the population of high Sox2-expressing cells. Sox 2 -high/Ki671 + cells represented $1.9 \pm 1 \%$ of total cells in the tion of TaP proliferation in the SEZ. They also revealed a migration phenotype, with an increase in the appearance of Dcx-positive and proliferating cells on the medial side of the ventricle (Fig. 7), where normally only very few migrating cells are seen.

\section{Discussion}

The exact position of stem cells within their niche will be critical for the regulation of cell behavior, as it will determine to which extracellular cues the stem cell is exposed. In the case of the SEZ neurogenic niche, both the ventricle (CSF, ependymal layer) and the vasculature have been implicated in the regulation of neurogenesis (Sawamoto et al., 2006; Mirzadeh et al., 2008; Shen et al., 2008; Tavazoie et al., 2008). In keeping with this, our analysis revealed that the periventricular area where neurogenesis occurs is characterized by significantly higher vascularization compared to non-neurogenic areas, a result of the penetration of the blood vessel network nearer to the ventricle. This specialization of the vasculature of the niche might be very important not only for homeostatic neurogenesis (i.e., the turnover seen in the undamaged CNS) but also for the regenerative responses after injury, since inflammation mediated by the innate microglia and the blood vessel-derived infiltrating T-cells has been shown to modulate NSC and precursor behavior (Pluchino et al., 2008; Ekdahl et al., 2009). Interestingly, however, within the 3D SEZ microenvironment the distribution of mitotic cells within both the normal and regenerating tissue was not tightly linked to blood vessels, with either NSCs or precursors going through mitosis at a diversity of distances from $<5 \mu \mathrm{m}$ to $>30 \mu \mathrm{m}$ from the vessels. This is not to say that NSCs do not receive signals from vessels, as previous work has shown that fine processes from astrocytes can extend significant distances to contact blood vessels (Mirzadeh et al., 2008). However, as the distance from the ventricular wall emerged as a strong limiting factor, with all mitotic activity being restricted within a 20 - $\mu \mathrm{m}$-thick zone adjacent to the ventricle, we conclude that the ependymal cell layer generates signals that may be at least as important as the vasculature in regulating the mi- 

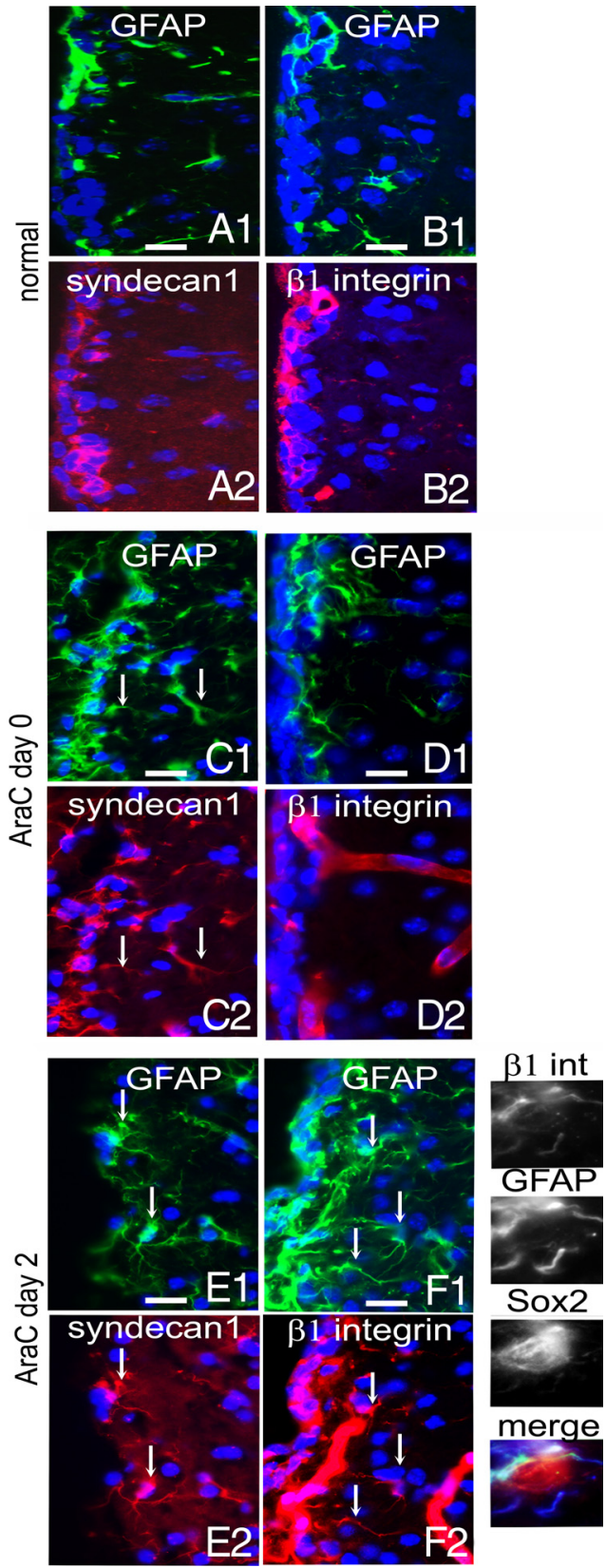

Figure 5. Laminin receptors in the normal and regenerating SEZ. Characteristic images of the SEZ from coronal sections immunostained for GFAP (green) and syndecan- 1 or $\beta 1$ integrin (red), with DAPl in blue. $A, B$, Expression of syndecan- 1 and $\beta 1$ integrin on astrocytes is very low in the normal SEZ. $C, D$, Immediately after the end of treatment with the anti-mitotic drug AraC (day $0, \boldsymbol{C}$ and $\boldsymbol{D}$ ), syndecan-1 expression is upregulated on astrocytes (examples of doublepositive cells indicated by arrows in $($ ), while $\beta 1$ integrin is still expressed only on ependymal cells and blood vessels $(\boldsymbol{D})$. Note the decrease in overall $\beta 1$ integrin immunoreactivity caused by the absence of TaPs and NBs due to AraC treatment (compare $\boldsymbol{B}$ and $\boldsymbol{D}$ ). Two days after AraC treatment, when NSCs become mitotic to regenerate the niche, expression of $\beta 1$ integrin is also upregulated on SEZ astrocytes (examples of syndecan- 1 and $\beta 1$ integrin-positive astrocytes are indicated by arrows in $\boldsymbol{E}$ and $\boldsymbol{F}$, respectively). At the right of $\boldsymbol{D}$, a higher-power view of a triple-labeled section is shown, illustrating a GFAP $+/ \beta 1$ integrin $+/$ Sox $2+$ cell that is therefore a NSC. Lateral ventricle is to the left in all images. Scale bars, $20 \mu \mathrm{m}$.

totic activity of stem and precursor cells in both the homeostatic and regenerating niche.

The nature of these signals remains to be determined, as only a few possible ependyma-derived regulators of neurogenesis have been identified previously, such as pigment epithelium-derived factor (Ramírez-Castillejo et al., 2006) and molecules of the bone
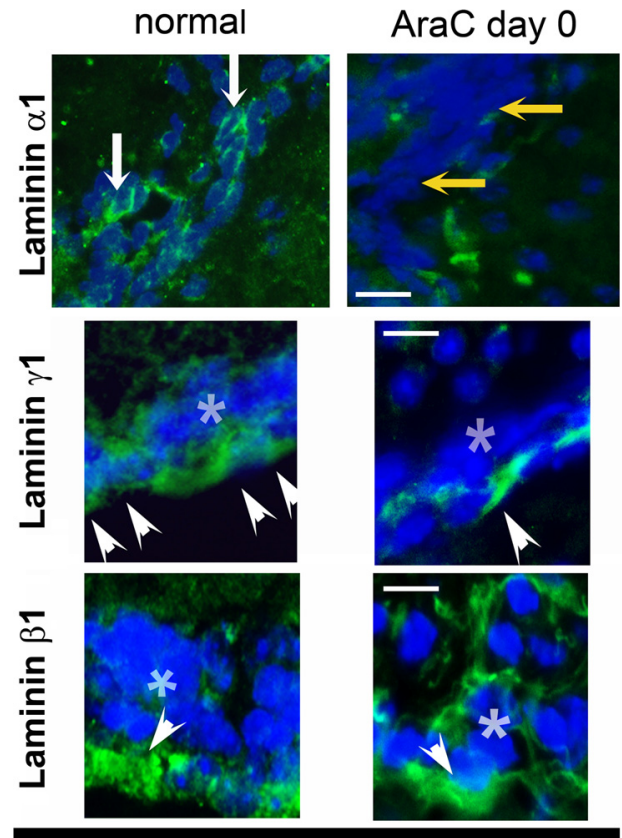

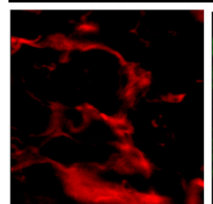

Laminin $\beta 1$

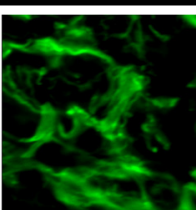

GFAP

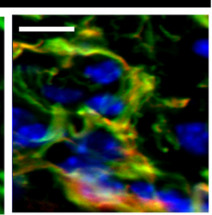

Figure 6. Laminin expression in the normal and regenerating SEZ. Characteristic images of the SEZ from coronal sections immunostained for different laminin chains. In the normal SEZ (shown in the left upper 3 panels), laminin immunoreactivity (green, with DAPI in blue) is high around clusters of cells. White arrows in the top panel indicate laminin $\alpha 1$ immunoreactivity at the dorsal horn of the SEZ, while stars in the middle panels indicate small clusters of cells in the SEZ after immunostaining with laminin $\gamma 1$ and laminin $\beta 1$. Laminin expression is also high at the ependymal cell layer (arrowheads in middle panels where the lateral ventricle is at the bottom). After AraC treatment (shown in the right upper 3 panels), resulting in the ablation of TaPs and NBs, the laminin content of the niche is decreased (yellow arrows at the top and stars in the middle panels indicate groups of cells in areas similar to the ones shown at the left) although it remains high around ependymal cells (arrowheads). One exception is the expression of laminin $\beta 1$, whose immunoreactivity is maintained (as shown in the lowest of this set of panels) and colocalized with GFAP + processes as shown in the set of three panels at the bottom of the figure, where a section has been double labeled for laminin $\beta 1$ (red) and GFAP (green). Scale bars, $10 \mu \mathrm{m}$.

morphogenetic protein pathway (Lim et al., 2000; Colak et al., 2008). Interestingly, and in support of the hypothesis that ependymal cells provide critical signals for neurogenesis, in nonneurogenic periventricular regions an additional layer of astrocytic processes running parallel to ependymal cells is observed. Thus, it is only within the neurogenic area that the subependymal region is separated from the ventricle only by the ependymal cell monolayer. Moreover, specific subtypes of ependymal cells (e.g., E2 bicilia cells) are observed exclusively in the neurogenic region of the ventricular wall (Mirzadeh et al., 2008). Nevertheless, the possible role of ependymal cells in the regulation of adult NSCs remains controversial since hippocampal neurogenesis occurs in a niche devoid of ependymal cells (Riquelme et al., 2008), albeit one producing different types of neurons via intermediate progenitors distinct from those seen in the SEZ (Seaberg and van der Kooy, 2002; Seri et al., 2004). In the future it will therefore be important to extend this type of structural investigation to other CNS niches and also to include in the analysis other cell types, 


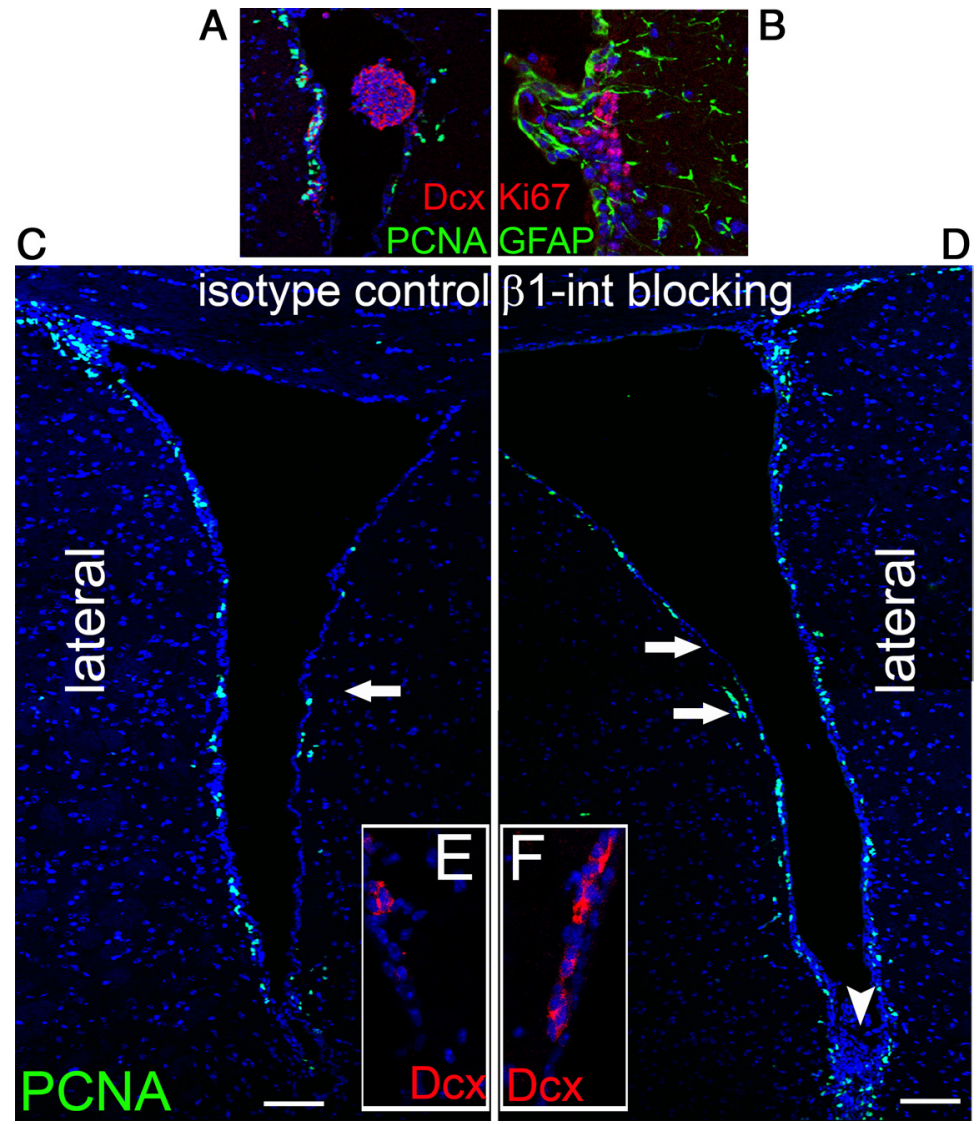

Figure 7. Effects of blocking $\beta 1$ integrin. $A, B, D$, Infusion of a $\beta 1$ integrin-blocking antibody in the lateral ventricle for $3 \mathrm{~d}$ resulted in disruption of the ventricular wall and in the appearance of $D c x+$ neuroblast clusters within the ventricle $(A)$ and at the bottom of the ventricle (arrowhead in $\boldsymbol{D}$ ), as well as in protrusions of the ventricular wall ( $\boldsymbol{B}$ ) consisting of GFAP + astrocytes and dividing cells (Ki67+). $\mathbf{C}-\boldsymbol{F}$, In addition, it resulted in the increased occurrence of proliferating cells at the medial side (arrows in $\boldsymbol{C}, \boldsymbol{D})$; these cells were mainly $D c x+$ neuroblasts $[\boldsymbol{E}$ and $\boldsymbol{F}$ show high magnifications of the medial wall of the ventricles from sections adjacent to the ones shown in $\boldsymbol{C}$ and $\boldsymbol{D}$, respectively; note the increased number of $D c x+$ cells (red) in $\boldsymbol{F}$. Scale bars, $50 \mu \mathrm{m}$.

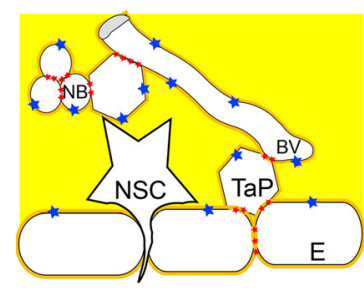

normal

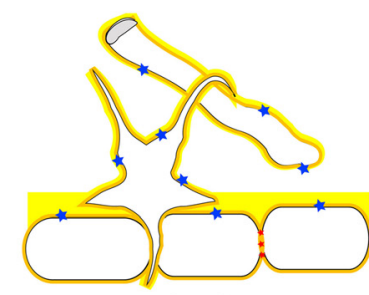

day0

(pre-neurogenic)

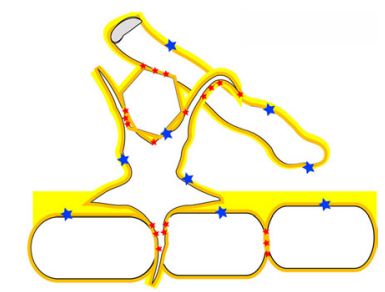

day2 (neurogenic)

\section{Laminins}

Figure 8. Cell-cell and cell-ECM interactions in the normal and regenerating SEZ. In the normal niche (left), ependymal cells, blood vessels, and precursors produce laminin (orange outlining) and express laminin receptors (blue and red stars), while NSCs do not express detectable levels of laminin receptors. Immediately after the depletion of TaPs and NBs (elicited by treatment with $\operatorname{AraC}$ - day 0 , middle), the niche microenvironment becomes depleted of laminins, with the exception of NSC-produced laminin $\beta 1$ and laminins correlated with blood vessels and ependymal cells. In addition, NSCs upregulate expression of syndecan- 1 and lutheran. Two days later (day 2, right), when NSCs become mitotic to regenerate the niche, $\beta 1$ integrin expression is also upregulated on NSCs, possibly regulating proliferation and interactions with adjacent, laminin-positive cells. BV, Blood vessel; E, ependymal cell.

such as microglia, that have been shown to regulate the behavior of neuronal progenitors (Walton et al., 2006).

Previous experimental work has shown that the SEZ is rich in ECM molecules, such as fibronectin and laminins $\beta 1$ and $\gamma 1$ (Mercier et al., 2002), chondroitin sulfate proteoglycans (Thomas et al., 1996; Akita et al., 2008), and tenascin-C (Peretto et al., 2005; de Chevigny et al., 2006; Kazanis et al., 2007). Here, we showed that NSCs and precursors are exposed to high levels of many additional laminin chains within the niche, including laminin $\alpha 5$. Laminins are important for proliferation and survival of neuronal progenitors (Barnabé-Heider et al., 2005; Hall et al., 2008) and for hippocampal regeneration (Grimpe et al., 2002) and regulate growth factor concentrations in the SEZ (Kerever et al., 2007). Moreover, recent in vivo studies have revealed a role of laminins and especially of laminin 511 (the $\alpha 5 \beta 1 \gamma 1$ trimer), produced both by vessel endothelial cells and other sources, in the regulation of adult stem cells in the skin (Paquet-Fifield et al., 2009) and pancreas (Otonkoski et al., 2008). In vitro work has also demonstrated a role for $\alpha 5$ laminins in the survival and proliferation of embryonic stem cells (Yoshihara et al., 2007; Domogatskaya et al., 2008; Evseenko et al., 2009; Vuoristo et al., 2009). This laminin may therefore have a significant role in the regulation of adult NSCs within the SEZ.

Our experiments indicate at least three different sources of laminins. The marked reduction of the laminin content of the niche after ablation of precursors revealed that cells of the NSC lineage are one major source of these molecules. In contrast, laminin immunostaining around ependymal cells and blood vessels remained stable after AraC treatment, showing that both these two additional sources-containing cells that are not affected by anti-mitotic treatment (Doetsch et al., 1999) — are producing laminins independently of the presence of precursors. Finally the preservation of lami$\operatorname{nin} \beta 1$ expression in the parenchyma of the SEZ after AraC treatment, and its colocalization with astrocytic cell bodies and processes, suggests that SEZ astrocytes may represent a fourth source exhibiting a celltype-specific expression pattern of laminins seen only following injury.

How do NSCs and precursors interact with the ECM derived from all of the cellular components of the niche? We found that NSCs and precursors express different levels of laminin receptors, with the latter expressing high levels of $\alpha 6 \beta 1$ integrin, syndecan-1, and lutheran while the former did not express detectable levels of these same receptors. Specifically for $\beta 1$ integrin, this result was confirmed with neurosphere generation assays after FACS separation of SEZ cells by expression levels of Sox 2 and $\beta 1$ integrin. $\beta 1$ Integrin has been previously identified as a marker of actively dividing neuronal progenitors (Campos et al., 2004; Nagato et al., 2005; Hall et al., 2006). Therefore, we propose that expression of ECM receptors such as $\alpha 6 \beta 1$ integrin could be a mechanism that NSCs use to 
regulate their activity (Fig. 8). Although NSCs and precursors reside in similar niche domains (Mirzadeh et al., 2008) and are thus exposed to similar extracellular signals from the ECM, during normal conditions NSCs will have limited interaction with their microenvironment (as a result of low receptor expression) and so remain relatively quiescent. This conclusion is supported by the lack of any effect on NSC behavior in the $\beta 1$ integrinblocking experiments. When NSCs are stimulated to become active, to replenish the depleted niche after AraC infusions, their position relative to the ventricle and the vasculature remains unaltered, but they upregulate expression of $\alpha 6 \beta 1$ integrin, lutheran, and syndecan-1 and thus increase their interaction with their cellular and extracellular environment (Fig. 8). $\beta 1$ Integrin has been shown to mediate interactions with laminin 511 (Otonkoski et al., 2008; Evseenko et al., 2009; Vuoristo et al., 2009), while lutheran is a laminin $\alpha 5$-specific receptor (Rahuel et al., 2008). Syndecan-1 has been previously shown to promote proliferation of breast cancer cells (Blaess et al., 2004) and to enhance FGF2 activity (Filla et al., 1998 ) via paracrine activity, in some cases signaling in cooperation with integrins (Banerjee et al., 2006). The correlation between the level of activity of adult NSCs and alterations in laminin-integrin interactions is reminiscent of recent findings in the follicle stem cell niche of the Drosophila ovary (O'Reilly et al., 2008) where follicle stem cells cell autonomously control their self-renewing behavior in a two-step process: first by producing laminin and second by upregulating integrin expression.

What is the role of $\beta 1$ integrin on activated NSCs and precursors? The increased proliferation of precursors after antibody blocking of $\beta 1$ integrin activity, similar to results obtained previously after antibody blocking of $\alpha 6$ integrin (Shen et al., 2008), suggests that an important function of integrins might be to control levels of proliferation in actively dividing cells. Here, the observation that increased proliferation was seen in cells expressing high levels of Sox 2 suggests that the affected population is the TaPs rather than NBs, but further work using specific TaP markers such as Mash1 and Olig2 (Hack et al., 2005) and cell surface markers of activated NSCs and TaPs such as the EGF receptor (Pastrana et al., 2009) will be required to confirm this. In the intestine adult stem cell niche, perturbation of $\beta 1$ integrin also resulted in increased proliferation of progenitors, partially due to defective Shh signaling (Willaime-Morawek et al., 2006). Another aspect of integrin function is the control of cell migration, and it has been shown that genetic deletion or blocking of $\beta 1$ integrin results in disrupted architecture of the rostral migratory stream (Blaess et al., 2004) and altered migration of NBs (Emsley and Hagg, 2003). In agreement with this, we showed that blocking $\beta 1$ integrin resulted in increased ectopic migration of NBs at the medial side of the LVs.

In conclusion, our descriptive and functional study highlights three important properties of the cellular and extracellular architecture of the SEZ in the regulation of stem cell behavior: first, the greater proximity of mitotic cells to the ependymal cells than to blood vessels; second, the lack of change in this architecture during NSC activation and niche regeneration; and third, the generation by neural precursor cells of their own ECM microenvironment, the interaction to which depends on the state of activation and variation in the level of receptor expression. The recognition that ependymal cells are likely to be an important source of signals in addition to blood vessels for the regulation of NSC behavior, and that NSCs alter their interactions with their microenvironment during successful regeneration not by exposure to a different ECM but by altering their receptor expression, has significant implications in regenerative medicine and in any attempt to transplant (into areas of degeneration) neural stem and precursor cells while providing them with the signals required to retain their self-renewing capacity and to promote repair.

\section{References}

Akita K, von Holst A, Furukawa Y, Mikami T, Sugahara K, Faissner A (2008) Expression of multiple chondroitin/dermatan sulfotransferases in the neurogenic regions of the embryonic and adult central nervous system implies that complex chondroitin sulfates have a role in neural stem cell maintenance. Stem Cells 26:798-809.

Banerjee I, Yekkala K, Borg TK, Baudino TA (2006) Dynamic interactions between myocytes, fibroblasts, and extracellular matrix. Ann N Y Acad Sci 1080:76-84.

Barnabé-Heider F, Wasylnka JA, Fernandes KJ, Porsche C, Sendtner M, Kaplan DR, Miller FD (2005) Evidence that embryonic neurons regulate the onset of cortical gliogenesis via cardiotrophin-1. Neuron 48:253-265.

Blaess S, Graus-Porta D, Belvindrah R, Radakovits R, Pons S, LittlewoodEvans A, Senften M, Guo H, Li Y, Miner JH, Reichardt LF, Müller U (2004) $\beta 1$-Integrins are critical for cerebellar granule cell precursor proliferation. J Neurosci 24:3402-3412.

Campos LS, Leone DP, Relvas JB, Brakebusch C, Fässler R, Suter U, ffrenchConstant C (2004) Betal integrins activate a MAPK signalling pathway in neural stem cells that contributes to their maintenance. Development 131:3433-3444

Charbord P, Moore K (2005) Gene expression in stem cell-supporting stromal cell lines. Ann N Y Acad Sci 1044:159-167.

Colak D, Mori T, Brill MS, Pfeifer A, Falk S, Deng C, Monteiro R, Mummery C, Sommer L, Götz M (2008) Adult neurogenesis requires Smad4mediated bone morphogenic protein signaling in stem cells. J Neurosci 28:434-446.

Coskun V, Wu H, Blanchi B, Tsao S, Kim K, Zhao J, Biancotti JC, Hutnick L, Krueger RC Jr, Fan G, de Vellis J, Sun YE (2008) CD133+ neural stem cells in the ependyma of mammalian postnatal forebrain. Proc Natl Acad Sci U S A 105:1026-1031.

de Chevigny A, Lemasson M, Saghatelyan A, Sibbe M, Schachner M, Lledo PM (2006) Delayed onset of odor detection in neonatal mice lacking tenascin-C. Mol Cell Neurosci 32:174-186.

Doetsch F, García-Verdugo JM, Alvarez-Buylla A (1997) Cellular composition and three-dimensional organization of the subventricular germinal zone in the adult mammalian brain. J Neurosci 17:5046-5061.

Doetsch F, García-Verdugo JM, Alvarez-Buylla A (1999) Regeneration of a germinal layer in the adult mammalian brain. Proc Natl Acad Sci U S A 96:11619-11624.

Domogatskaya A, Rodin S, Boutaud A, Tryggvason K (2008) Laminin-511 but not $-332,-111$, or -411 enables mouse embryonic stem cell selfrenewal in vitro. Stem Cells 26:2800-2809.

Ekdahl CT, Kokaia Z, Lindvall O (2009) Brain inflammation and adult neurogenesis: the dual role of microglia. Neuroscience 158:1021-1029.

Ellis P, Fagan BM, Magness ST, Hutton S, Taranova O, Hayashi S, McMahon A, Rao M, Pevny L (2004) SOX2, a persistent marker for multipotential neural stem cells derived from embryonic stem cells, the embryo or the adult. Dev Neurosci 26:148-165.

Emsley JG, Hagg T (2003) Alpha6betal integrin directs migration of neuronal precursors in adult mouse forebrain. Exp Neurol 183:273-285.

Evseenko D, Schenke-Layland K, Dravid G, Zhu Y, Hao QL, Scholes J, Wang XC, Maclellan WR, Crooks GM (2009) Identification of the critical extracellular matrix proteins that promote human embryonic stem cell assembly. Stem Cells Dev 18:919-928.

Filla MS, Dam P, Rapraeger AC (1998) The cell surface proteoglycan syndecan-1 mediates fibroblast growth factor-2 binding and activity. J Cell Physiol 174:310-321.

Grimpe B, Dong S, Doller C, Temple K, Malouf AT, Silver J (2002) The critical role of basement membrane-independent laminin $\gamma 1$ chain during axon regeneration in the CNS. J Neurosci 22:3144-3160.

Hack MA, Saghatelyan A, de Chevigny A, Pfeifer A, Ashery-Padan R, Lledo PM, Götz M (2005) Neuronal fate determinants of adult olfactory bulb neurogenesis. Nat Neurosci 8:865-872.

Hall PE, Lathia JD, Miller NG, Caldwell MA, ffrench-Constant C (2006) Integrins are markers of human neural stem cells. Stem Cells 24:2078-2084.

Hall PE, Lathia JD, Caldwell MA, ffrench-Constant C (2008) Laminin en- 
hances the growth of human neural stem cells in defined culture media. BMC Neurosci 9:71.

Kazanis I, Belhadi A, Faissner A, ffrench-Constant C (2007) The adult mouse subependymal zone regenerates efficiently in the absence of tenascin-C. J Neurosci 27:13991-13996.

Kerever A, Schnack J, Vellinga D, Ichikawa N, Moon C, Arikawa-Hirasawa E, Efird JT, Mercier F (2007) Novel extracellular matrix structures in the neural stem cell niche capture the neurogenic factor fibroblast growth factor 2 from the extracellular milieu. Stem Cells 25:2146-2157.

Kiel MJ, He S, Ashkenazi R, Gentry SN, Teta M, Kushner JA, Jackson TL, Morrison SJ (2007) Haematopoietic stem cells do not asymmetrically segregate chromosomes or retain BrdU. Nature 449:238-242.

Lathia JD, Patton B, Eckley DM, Magnus T, Mughal MR, Sasaki T, Caldwell MA, Rao MS, Mattson MP, ffrench-Constant C (2007) Patterns of laminins and integrins in the embryonic ventricular zone of the CNS. J Comp Neurol 505:630-643.

Lim DA, Tramontin AD, Trevejo JM, Herrera DG, García-Verdugo JM, Alvarez-Buylla A (2000) Noggin antagonizes BMP signaling to create a niche for adult neurogenesis. Neuron 28:713-726.

Mercier F, Kitasako JT, Hatton GI (2002) Anatomy of the brain neurogenic zones revisited: fractones and the fibroblast/macrophage network. J Comp Neurol 451:170-188.

Mirzadeh Z, Merkle FT, Soriano-Navarro M, Garcia-Verdugo JM, AlvarezBuylla A (2008) Neural stem cells confer unique pinwheel architecture to the ventricular surface in neurogenic regions of the adult brain. Cell Stem Cell 3:265-278.

Morshead CM, Reynolds BA, Craig CG, McBurney MW, Staines WA, Morassutti D, Weiss S, van der Kooy D (1994) Neural stem cells in the adult mammalian forebrain: a relatively quiescent subpopulation of subependymal cells. Neuron 13:1071-1082.

Nagato M, Heike T, Kato T, Yamanaka Y, Yoshimoto M, Shimazaki T, Okano H, Nakahata T (2005) Prospective characterization of neural stem cells by flow cytometry analysis using a combination of surface markers. J Neurosci Res 80:456-466.

O'Reilly AM, Lee HH, Simon MA (2008) Integrins control the positioning and proliferation of follicle stem cells in the Drosophila ovary. J Cell Biol 182:801-815.

Otonkoski T, Banerjee M, Korsgren O, Thornell LE, Virtanen I (2008) Unique basement membrane structure of human pancreatic islets: implications for beta-cell growth and differentiation. Diabetes Obes Metab 10 [Suppl 4]:119-127.

Panchision DM, Chen HL, Pistollato F, Papini D, Ni HT, Hawley TS (2007) Optimized flow cytometric analysis of central nervous system tissue reveals novel functional relationships among cells expressing CD133, CD15, and CD24. Stem Cells 25:1560-1570.

Paquet-Fifield S, Schlüter H, Li A, Aitken T, Gangatirkar P, Blashki D, Koelmeyer R, Pouliot N, Palatsides M, Ellis S, Brouard N, Zannettino A, Saunders N, Thompson N, Li J, Kaur P (2009) A role for pericytes as microenvironmental regulators of human skin tissue regeneration. J Clin Invest 119:2795-2806.

Pastrana E, Cheng LC, Doetsch F (2009) Simultaneous prospective purification of adult subventricular zone neural stem cells and their progeny. Proc Natl Acad Sci U S A 106:6387-6392.

Peretto P, Giachino C, Aimar P, Fasolo A, Bonfanti L (2005) Chain formation and glial tube assembly in the shift from neonatal to adult subventricular zone of the rodent forebrain. J Comp Neurol 487:407-427.
Pluchino S, Muzio L, Imitola J, Deleidi M, Alfaro-Cervello C, Salani G, Porcheri C, Brambilla E, Cavasinni F, Bergamaschi A, Garcia-Verdugo JM, Comi G, Khoury SJ, Martino G (2008) Persistent inflammation alters the function of the endogenous brain stem cell compartment. Brain 131:2564-2578.

Rahuel C, Filipe A, Ritie L, El Nemer W, Patey-Mariaud N, Eladari D, Cartron JP, Simon-Assmann P, Le Van Kim C, Colin Y (2008) Genetic inactivation of the laminin alpha5 chain receptor Lu/BCAM leads to kidney and intestinal abnormalities in the mouse. Am J Physiol Renal Physiol 294:F393-F406.

Ramírez-Castillejo C, Sánchez-Sánchez F, Andreu-Agulló C, Ferrón SR, Aroca-Aguilar JD, Sánchez P, Mira H, Escribano J, Fariñas I (2006) Pigment epithelium-derived factor is a niche signal for neural stem cell renewal. Nat Neurosci 9:331-339.

Riquelme PA, Drapeau E, Doetsch F (2008) Brain micro-ecologies: neural stem cell niches in the adult mammalian brain. Philos Trans R Soc Lond B Biol Sci 363:123-137.

Sawamoto K, Wichterle H, Gonzalez-Perez O, Cholfin JA, Yamada M, Spassky N, Murcia NS, Garcia-Verdugo JM, Marin O, Rubenstein JL, Tessier-Lavigne M, Okano H, Alvarez-Buylla A (2006) New neurons follow the flow of cerebrospinal fluid in the adult brain. Science 311:629-632.

Scadden DT (2006) The stem-cell niche as an entity of action. Nature 441:1075-1079.

Seaberg RM, van der Kooy D (2002) Adult rodent neurogenic regions: the ventricular subependyma contains neural stem cells, but the dentate gyrus contains restricted progenitors. J Neurosci 22:1784-1793.

Seri B, García-Verdugo JM, Collado-Morente L, McEwen BS, Alvarez-Buylla A (2004) Cell types, lineage, and architecture of the germinal zone in the adult dentate gyrus. J Comp Neurol 478:359-378.

Shen Q, Wang Y, Kokovay E, Lin G, Chuang SM, Goderie SK, Roysam B, Temple S (2008) Adult SVZ stem cells lie in a vascular niche: a quantitative analysis of niche cell-cell interactions. Cell Stem Cell 3:289-300.

Tavazoie M, Van der Veken L, Silva-Vargas V, Louissaint M, Colonna L, Zaidi B, Garcia-Verdugo JM, Doetsch F (2008) A specialized vascular niche for adult neural stem cells. Cell Stem Cell 3:279-288.

Thomas LB, Gates MA, Steindler DA (1996) Young neurons from the adult subependymal zone proliferate and migrate along an astrocyte, extracellular matrix-rich pathway. Glia 17:1-14.

Vuoristo S, Virtanen I, Takkunen M, Palgi J, Kikkawa Y, Rousselle P, Sekiguchi K, Tuuri T, Otonkoski T (2009) Laminin isoforms in human embryonic stem cells: synthesis, receptor usage and growth support. J Cell Mol Med 13:2622-2633.

Walton NM, Sutter BM, Laywell ED, Levkoff LH, Kearns SM, Marshall GP 2nd, Scheffler B, Steindler DA (2006) Microglia instruct subventricular zone neurogenesis. Glia 54:815-825.

Willaime-Morawek S, Seaberg RM, Batista C, Labbé E, Attisano L, Gorski JA, Jones KR, Kam A, Morshead CM, van der Kooy D (2006) Embryonic cortical neural stem cells migrate ventrally and persist as postnatal striatal stem cells. J Cell Biol 175:159-168.

Yoshihara H, Arai F, Hosokawa K, Hagiwara T, Takubo K, Nakamura Y, Gomei Y, Iwasaki H, Matsuoka S, Miyamoto K, Miyazaki H, Takahashi T, Suda T (2007) Thrombopoietin/MPL signaling regulates hematopoietic stem cell quiescence and interaction with the osteoblastic niche. Cell Stem Cell 1:685-697. 